\title{
Diver-operated versus remote-controlled chambers used in underwater tracer experiments
}

\author{
E. J.ZilliouX \\ Rosenstiel School of Marine and Atmospheric Science, University of Miami; \\ Miami, Florida, USA
}

\begin{abstract}
KURZFASSUNG: Von Tauchern eingesetzte versus ferngesteuerte Kammern bei Unterwasser-Tracerexperimenten. Zwei Verfahren, die in situ bei ernährungsbiologischen Untersuchungen an marinen Copepoden angewendet worden sind, werden beschrieben und kritisch verglichen. Die erste Methode erfordert den ständigen Einsatz von Tauchern. Sie bedienen Plastikbeutel, die in bestimmten Abständen von der Oberfläche bis zu $60 \mathrm{~m}$ Tiefe angebunden werden. In die Beutel werden die Versuchstiere eingesetzt, vor allem Undinula vulgaris. Mikrozooplankton, mit ${ }^{65} \mathrm{Zn}$ markiert, dient den Copepoden als Nahrung. Nach Injektion markierter Nahrungstiere in die Plastikbeutel wird das Experiment durch Abtöten der Versuchstiere mit einem Plankton-Fixierungsmittel beendet. Das Maß der Ingestion und Defäkation der Nahrung wird danach anhand der Verteilung der Radioaktivität bestimmt. In einem zweiten Versuchsprogramm wird ein Behälter aus Plexiglas innerhalb eines PVC-Rahmens benutzt, der durch Fernsteuerung bedient werden kann. Dieser dient der Aufnahme der Copepoden und der Nahrungsorganismen. Nach Beendigung des Versuchs wird die Flüssigkeit durch ein Membranfilter abgelassen und die Verteilung der Radioaktivität in den Copepoden gemessen, die auf dem Filter zurückbleiben. Zwischen Oberfläche und $200 \mathrm{~m}$ Tiefe wurden mehrere derartige, an einem langen Draht befestigten Behälter eingesetzt. Vor- und Nachteile beider Verfahren werden diskutiert.
\end{abstract}

\section{INTRODUCTION}

A program was recently begun to study initial feeding responses of vertically migrating copepods. Of importance as possible stimuli were all natural parameters which vary or usually vary with depth through the normal range of the subject vertical migrator. These included pressure, light quantity and quality, temperature, concentration of food organisms and dissolved organics. The age and history of the vertical migrator may also be expected to modify behavioral responses. It seemed apparent that the only feasible way to study collective effects of these variables would be to conduct experiments in the natural environment. Unfortunately, the difficulty of designing in situ experiments has limited most zooplankton investigations of this type to analysis of gut contents from preserved or recently collected animals. Two important exceptions are limnological studies by GLIWICZ (1968) and HANEY (1971) which measured grazing rates of zooplankton caught in specially designed traps. Because there was no concentration of the original plankton sample, however, these devices would 
be effective only in areas of high productivity. The lack of a mechanism to terminate the experimental feeding period in situ further limits these traps to very shallow areas where continued grazing during retrieval would not significantly bias the results. Experimental feeding studies with pelagic marine zooplankton generally have been carried out only in the more easily controlled conditions of the laboratory.

Although the effects of independent variables as well as certain synergistic effects should be evaluated in the laboratory, it was obvious that extrapolation from the results of a large number of laboratory experiments to explain feeding responses in a complex natural environment would be less than valid. Two approaches were developed, therefore, which allowed an investigation of the problem by controlled in situ experiments.

First, divers descended to various depths to manipulate experiments contained in polyethylene bags. Secondly, an acrylic chamber was designed to contain the experiment at depth and allow necessary functions to be carried out by remote control.

A description and critical comparison of these methods are reported in this paper. The experimental results are preliminary and will be reported in detail in a later publication.

\section{PREPARATION OF EXPERIMENTAL MATERIAL}

Most of the feeding experiments were carried out with the calanoid copepod Undinula vulgaris (DANA). U. vulgaris is a relatively large carnivore and is abundant in the waters of the Bahamas as well as in the Gulf of Mexico and the Gulf Stream to the south and east of Florida where later experiments were conducted. Tables of vertical distribution published by OWRE \& Foyo (1967) show on two separate days maximum midday concentrations at $75 \mathrm{~m}$ and $274 \mathrm{~m}$ respectively. Maximum midnight concentrations on both days were at the surface. In this work, maximum surface concentrations of $U$. vulgaris were always found between sunset and total night darkness. Experimental animals usually were collected at dusk by successive ten minute tows with $1 / 2 \mathrm{~m} 200 \mu \mathrm{m}$ mesh nets having soft, vented cod-end buckets to minimize damage during towing. The animals were isolated by pipet and placed in flow-through tanks aboard ship (described by ZrLLoux \& LACKIE 1970). The water was collected from one meter depth and circulated without filtration to supply a normal food ration during the holding period.

Microzooplankton labeled with ${ }^{65} \mathrm{Zn}$ was used as food in the experiments. For the purposes of this work, microzooplankton was defined by the method of its collection. Mixed plankton samples, collected with $1 / 2 \mathrm{~m} 35 \mu \mathrm{m}$ mesh nets, were placed in a large tank of unfiltered seawater. The contents of this tank were slowy filtered through a siphon fitted with a large funnel covered with $200 \mu \mathrm{m}$ nylon mesh. The resulting filtrate (microzooplankton), consisting primarily of copepod nauplii and early copepodite stages, also was maintained in flow-through tanks until needed.

${ }^{65} \mathrm{Zn}$ label was incorporated into the microzooplankton both by absorption and by ingestion of labeled food. $200 \mu \mathrm{Ci}$ of ${ }^{65} \mathrm{Zn}$ first was added to one liter of an algal culture (usually lsochrysis galbana PARKE) in its logarithmic growth phase. Several 
hours later, one liter of concentrated microzooplankton was added directly to the labeled algal culture. Harvest was made after another period of several hours and just prior to the initiation of a feeding experiment (the time schedule here is not important as both algae and microzooplankton take up the isotope label very rapidly under these conditions). The labeled material was filtered through a $35 \mu \mathrm{m}$ nylon mesh and washed three times in seawater. An aliquot was placed on a tared membrane filter and washed twice with small amounts of freshwater. (Both the prepared filter and the filtrate would later be counted for radioactivity and the values summed in order to correct for possible loss during the freshwater wash. The prepared filter would then be weighed to dryness and the specific activity of microzooplankton food calculated in terms of activity per $\mathrm{mg}$ dry weight.) The remainder of the food was placed in plastic hypodermic syringes for use in the experiment.

\section{DESCRIPTION AND OPERATION OF IN SITU CHAMBERS}

\section{Diver-operated chamber}

A simple, inexpensive chamber was designed to contain experiments at depth and allow direct operational control by divers. Both clear and black polyethylene plastic, $0.15 \mathrm{~mm}$ and $0.2 \mathrm{~mm}$ thick, respectively, was fabricated into flexible bags approximately $30 \mathrm{~cm}$ long and $20 \mathrm{~cm}$ in diameter by heat sealing. Each bag contained two liters of seawater and access was gained through the open end of a horn approximately $20 \mathrm{~cm}$ long and $5 \mathrm{~cm}$ in diameter. A water-tight seal was made by rolling the horn up to the body of the bag and clamping the roll with an ordinary paper clamp. The metal clamps were sprayed with paint to retard corrosion but were usually discarded after two or three experiments. New bag chambers were used for each experiment. The polyethylene bags were contained in nylon fish-net bags $(19 \mathrm{~mm}$ stretch mesh) which were in turn tied to a line secured to the bottom and buoyed at the surface. A hole in the net bag allowed for extension of the horn when access to the experiment chamber was necessary.

A site off New Providence Island in the northern part of the Tongue of the Ocean was selected for the diving operation. Here, the bow anchorage was made in $18 \mathrm{~m}$ depth while the vessel's stern was over a precipitous wall which dropped from 30 to about $200 \mathrm{~m}$ and then, at only a slight slope from the vertical, continued down to over $300 \mathrm{~m}$. For several reasons the selection of this site was critical for the operation. With the use of a small skiff we were able to collect with plankton nets all of our vertically migrating experimental animals within a short distance of the anchored ship.

The experiment chambers were secured at intervals down the vertical wall. The alternative, which we rejected, would require divers to be suspended over deep water for the duration of the experiment and the necessary decompression period. The suitability of the site was further enhanced by a prevailing breeze, which held the vessel's stern directly over the dive site, and virtually no noticeable water currents. Deep hydro casts could easily be made during the same operation simply by slacking off the bow anchors. 


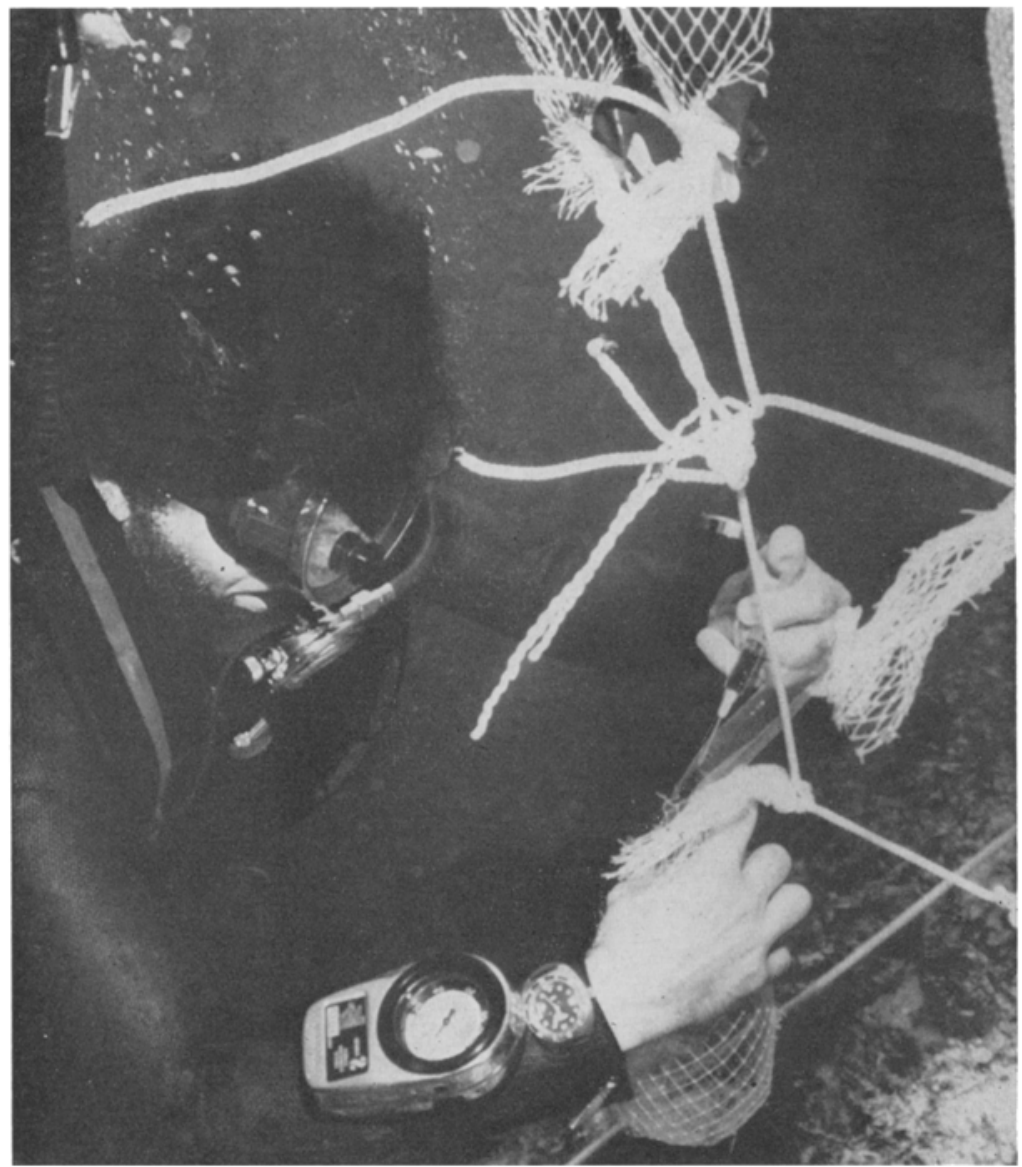

Fig. 1: Injection of polyethylene bag chamber with radioactive food. The bag is squeezed by the diver to extend the horn during injection. (Photo: J. GrFford)

A single polyethylene line was attached to a surface buoy and tied to a coral projection at the threshold of the wall. Loops were tied in the line just under the surface and at $15 \mathrm{~m}$. Two lines, one yellow and one white, were then tied at the threshold of the wall and brought down over the wall's surface to just beyond $60 \mathrm{~m}$ where they were again secured to a coral projection. Loops were tied in these lines at 30,45 and $60 \mathrm{~m}$.

An experiment was initiated by divers carrying down 20 bags previously loaded with 50 to 100 adult copepods each in unfiltered seawater. Two black bags and two clear bags were tied to the loops at each station.

The experimental animals were allowed to equilibrate at depth for at least 12 hours. Feeding commenced with the injection of labeled food. The experiment was terminated 20 minutes later by injection of a plankton fixative. The length of the feeding period was less than the minimum time from ingestion to defecation for the 
copepods at the highest ambient temperature encountered. After fixation, a new set of bags were tied to the alternate line for the next experiment and the bags of the completed experiment were removed and brought back to the ship's laboratory for processing.

The method of injection is illustrated in Figure 1.

\section{Remote-controlled chamber}

The remote-controlled chamber used here was a slight modification of the in situ separator (Fig. 2) described by Niskin (in press).

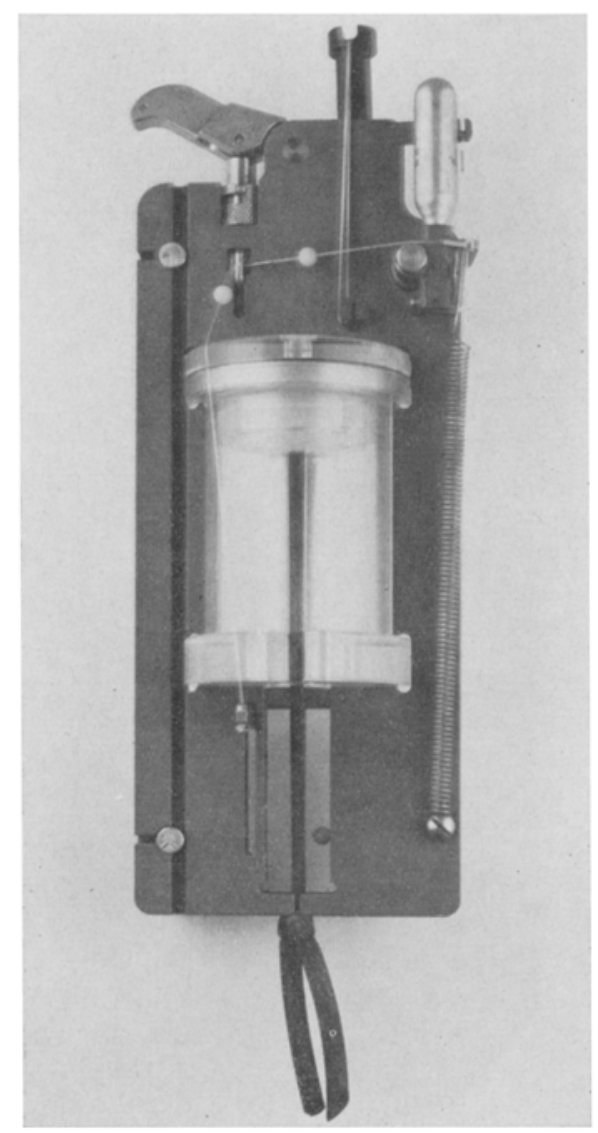

Fig. 2: In situ separator used with slight modification for remote-controlled underwater feeding experiments

The original design allowed the chamber to fill at depth by withdrawal of a piston causing water to enter through a one-way valve. For my use, the acrylic chamber is filled at the surface with usually 50 copepods in $600 \mathrm{ml}$ of unfiltered seawater. 
A very concentrated sample of labeled microzooplankton is contained in a $2.5 \mathrm{ml}$ hypodermic syringe (approximately $32 \mathrm{mg}$ dry weight in $1.6 \mathrm{ml}$ delivered volume). A conventional $\mathrm{CO}_{2}$ inflation assembly is coupled through a manifold to a modified syringe needle. Both syringe needles penetrate the chamber cover through holes sealed with silicon rubber cement.

Two operations are facilitated with the use of a double tripping mechanism. The first messenger partially depresses the trip lever which releases the syringe latch allowing injection of labeled food. The second messenger fully depresses the trip lever. This releases a restraining lanyard and allows piercing of the gas cartridge. The gas displaces the entire volume of seawater through a membrane filter located in the bottom of the cylinder.

The experimental procedure was similar to that already described for the diveroperated bag chambers. Four loaded chambers were lowered on a hydrowire to stations located at $200 \mathrm{~m}, 134 \mathrm{~m}, 67 \mathrm{~m}$ and just under the water's surface. Two hours were allowed for acclimation before injection of the food.

After retrieval of the chambers, they were dismantled and the experimental animals washed off the filter and processed for later counting.

During all experiments, temperature was recorded at depth either by the divers or by reversing thermometers on a second hydrowire. Spectroradiometer readings were also made by using an instrument enclosed in a water-tight housing.

\section{TEST RESULTS}

Two feeding experiments were carried out in the laboratory with acrylic chambers and both black and clear polyethylene bags. The purpose was to determine if any materials used in construction of the different vessels might selectively absorb the radioactive label which would give bias to experimental results. Because the specific

Table 1

Comparison of radioactivity recovered from acrylic and polyethylene experiment containers

\begin{tabular}{|c|c|c|c|c|}
\hline $\begin{array}{c}\text { Experiment } \\
\text { No. }\end{array}$ & $\begin{array}{l}\text { Experiment } \\
\text { container }\end{array}$ & $\begin{array}{l}\text { Total activity } \\
\text { recovered } \\
\text { (counts/min) }\end{array}$ & $\begin{array}{l}\text { Correction for } \\
\text { variations in } \\
\text { container } \\
\text { volume }\end{array}$ & $\begin{array}{l}\text { Deviation } \\
\text { from mean } \\
(\% / 0)\end{array}$ \\
\hline \multirow{3}{*}{ I } & acrylic chamber & 4795 & 14385 & +5.5 \\
\hline & $\begin{array}{l}\text { black bag } 1 \\
\text { black bag } 2 \\
\text { black bag } 3\end{array}$ & $\begin{array}{l}15055 \\
13721 \\
13755\end{array}$ & $\begin{array}{l}15055 \\
13721 \\
13755\end{array}$ & $\begin{array}{r}+10.4 \\
+\quad 0.7 \\
+\quad 0.9\end{array}$ \\
\hline & $\begin{array}{l}\text { clenr bag } 1 \\
\text { clear bag } 2 \\
\text { clear bag } 3\end{array}$ & $\begin{array}{l}12341 \\
11111 \\
15045\end{array}$ & $\begin{array}{l}12341 \\
11111 \\
15045\end{array}$ & $\begin{array}{r}9.4 \\
-18.5 \\
+10.4\end{array}$ \\
\hline \multirow{3}{*}{ II } & $\begin{array}{l}\text { acrylic chamber } 1 \\
\text { acrylic chamber } 2\end{array}$ & $\begin{array}{l}1,420,245 \\
1,302,659\end{array}$ & $\begin{array}{l}4,260,735 \\
3,907,977\end{array}$ & $\begin{array}{l}+1.0 \\
+7.4\end{array}$ \\
\hline & black bag & $4,234,650$ & $4,234,650$ & +0.3 \\
\hline & clear bag & $4,477,219$ & $4,477,219$ & +6.1 \\
\hline
\end{tabular}


activity of food inocula used in routine feeding experiments is quite variable, a much more highly active inoculum was used in the second test than in the first. In both experiments the acrylic chambers were filled with $500 \mathrm{ml}$ seawater and the polyethylene bags with $1500 \mathrm{ml}$ seawater. Fifty animals were added to the acrylic chambers and 150 to the bags. Undinula vulgaris was fed labeled microzooplankton in the first experiment and Acartia tonsa DANA was fed a labeled chloromonad, Dunaliella sp., in the second. In each case the animals were fed for a 20 minute period. The activity recovered from the animals and aliquots of the medium and suspended particulate material was summed to give the total activity recovered from each experiment container. The results (Table 1) indicate that although the percent deviation of activity from the mean is somewhat variable, a trapping of radioactivity cannot be attributed to different materials used in the containers tested.

\section{DISCUSSION AND CONCLUSIONS}

Both chambers described here were effective in the production of useful data and are still in use. For in situ experiments to be conducted at considerable depths, however, a mechanically operated chamber offers several advantages. The most obvious is that experiments can be planned at greater depths than accessible to a diver. The mechanical chamber is limited only by the volume and character of the selected gas. This difficulty could be avoided by substituting a second hypodermic syringe filled with fixative in place of the present gas injection system. A new chamber incorporating this change will soon be in use. A small pump also will be added to circulate seawater between the container and the ambient environment without affecting retention of experimental or food organisms.

Because we were investigating effects of depth, it was impossible to avoid periods of decompression for the divers. The required surface interval between dives further complicated planning of the experiments. Fewer diving experiments could be carried out within a given period, therefore, than we were able to conduct with the mechanical chambers. The unnecessarily long acclimation period for the diving experiments was a result of this difficulty in scheduling repetitive dives. The possibility of significant mortality during acclimation was thus an important disadvantage of the bag experiments.

Bags which were tied to the descending line of the buoy received considerable agitation from wave action. The surface bags were torn open and contents lost on two occasions. No difficulties of operation were experienced with the bags secured to a line along the bottom. On the other hand, mechanical difficulties were an occasional problem with the remote-controlled chambers. These chambers are still in the process of development, however, and it is expected that the difficulties will be eliminated with a few minor design changes.

The initial cost of the mechanical chambers is much more than the equipment needed for the bag experiments. This is offset by several factors. Two additional people are needed to operate deep bag experiments as a minimum of two teams of divers are required. The use of mechanical chambers results in a more efficient use of ship time both because of the greater number of experiments that can be conducted and because 
the selection of a satisfactory dive site is unnecessary. Maintenance of diving equipment must also be considered.

Bag chambers are more easily adaptable to a wide range of research demands. Ease of operation and excellent recovery of the experimental material would make these chambers the best choice for work that could be conducted fixed to the bottom at relatively shallow depths or operated by divers from an underwater habitat. For the work described here, however, the remote-operated mechanical chamber was more practicable.

\section{SUMMARY}

1. Two chambers, one diver-operated and the other remote-controlled, were developed for in situ feeding experiments.

2. Both chambers have been used effectively in numerous experiments with vertically migrating copepods fed ${ }^{65} \mathrm{Zn}$-labeled microzooplankton.

3. Laboratory results demonstrated no significant difference in recovered radioactivity due to differences in material or design of the two chambers.

4. Diver-operated chambers are initially much less expensive and are generally more adaptable to changes in experimental design.

5. Remote-operated chambers require less personnel and are necessary when determining effects of depth within the entire range common for vertically migrating zooplankton.

Acknowledgements. This paper is contribution No. 1603 from the Rosenstiel School of Marine and Atmospheric Science, University of Miami. It was supported by the National Science Foundation, Grant No. GB-19646. I am grateful to Dr. J. Bunt for the use of the remote-controlled chambers and the spectroradiometer. I am also indebted to $S$. Niskin for his assistance and suggestions in the modification of the remote-controlled chamber and in the design of the polyethylene bag chamber and for the photograph used in Figure 2. I also wish to thank S. Camthon, H. Chansang, L. Farmer, J. Gifford and J. Zawodny for their valuable technical assistance, and S. HARTshorn, Captain of the R/V CALANUS, for his ready help and friendly suggestions throughout the Tongue of the Ocean cruise of January, 1972.

\section{LITERATURE CITED}

GLIWICZ, Z. M., 1968. The use of anaesthetizing substance in studies on the food habits of zooplankton communities. Ekol. pol. (A) 16, 279-295.

HANEY, J. F., 1971. An in situ method for the measurement of zooplankron grazing rates. Limnol. Oceanogr. 16, 970-977.

Niskin, S. J., 1973. In situ separator. Bull. mar. Sci. (In press.)

OWRE, H. B. \& Foyo, M., 1967. Copepods of the Florida Current. Institute of Marine Science, University of Miami, Miami, Fla., 137 pp.

Zillroux, E. J. \& LACKIE, N. F., 1970. Advances in the continuous culture of planktonic copepods. Helgoländer wiss. Meeresunters. 20, 325-332.

Author's address: E. J. Zrutroux

Rosenstiel School of Marine \& Atmospheric Science

University of Miami

Rickenbacker Causeway

Miami, Florida 33149

USA 